\title{
An Empirical Evaluation of Legislative Reforms for E-Corporate Governance in Indian Companies
}

\author{
Prof. J.P. Sharma ${ }^{1}$, Dr. Sunaina Kanojia ${ }^{2}$ and Ms. Shasta Gupta ${ }^{3}$
}

\begin{abstract}
This paper attempts to analyze the opinion of shareholders and company secretaries on reforms ushered to enhance shareholders participation with the amendments to Companies Act 2013 towards electronic initiatives; to study the perceptions of company secretaries on newly introduced provisions on electronic board meetings and; to compare the opinions of shareholders and company secretaries on different aspects of electronic initiatives. Through primary data analysis using phenomenological analysis, logistic regression, independent sample t-test, one sample test and binomial test the evidence has been collated. Specifically, for electronic delivery of documents, its impact on the environment has come out to be insignificant, while the level of ease and comfort associated with it and its impact on cost reduction have come out to be the significant variables impacting the opinion of shareholders in favour of electronic mode. For electronic voting, level of ease, no risk of security and no issue of e-votes being less informed have turned out to be the significant variables for the shareholders. It has been found that spreading awareness is quintessential for all the three initiatives. $66.7 \%$ of company secretaries and $83.6 \%$ of the shareholders themselves have agreed that educating shareholders about various concepts of an electronic interface is the need of the hour.
\end{abstract}

JEL Classification: G38, G34, G32.

Keywords: Companies Act, Company Secretaries, Corporate governance, Electronic initiatives, Shareholders, India.

\footnotetext{
${ }^{1}$ Former Head \& Dean Department of Commerce, Delhi School of Economics, Tel: 91- 9910401777; E-mail: jaiprakash2509@gmail.com ,

${ }^{2}$ Associate Professor, Department of Commerce, Delhi School of Economics, University of Delhi, Tel: 919711144259; E-mail: sunainakanojia@gmail.com

${ }^{3}$ Assistant Professor, Sri Aurobindo (Morning) College, University of Delhi, India. Tel: 91- 9873481584; Email: shasta.gupta20@gmail.com
} 


\section{INTRODUCTION}

The study encompasses two areas which have earned large scale discourses worldwide corporate governance and its extension - electronic corporate governance. Corporate governance is about having multiple persons with a different set of duties to oversee the functioning and management of the company on behalf of all the shareholders and other stakeholders. The term electronic corporate governance signifies the utilization of electronic means in the exercising of corporate governance. (Beuthel, 2006).There are three broad domains through which shareholders get a direct role in overseeing and questioning the operations of the company -by receiving annual reports and other documents from the company; by voting on the resolutions in general meetings and; by attending the general meetings. For the purpose of this study, an emphasis is laid on the role of technology in these areas, i.e. sharing the reports and documents electronically with the shareholders, soliciting the votes on the resolutions through remote e-voting and providing the provision of electronic participation in general meetings. An attempt is made to test the pros and cons of the provisions on electronic board meetings which have been allowed in India since 2011. What level of adoption exists among the shareholders in the electronic mode? Which factors influence a shareholder to decide whether to participate electronically or physically? How has the experience of company secretaries been in conducting electronic delivery of documents, electronic voting and electronic board meetings? What is the opinion of shareholders and company secretaries about these initiatives? These are some of the prime questions to which answers have been explored through this study.

\section{LITERATURE REVIEW}

Though the existing literature available in the domain of e-governance is scant but very few studies reported with empirical evidence have also been referred. This segment explores the review of already existing literature in respect of three electronic initiatives, viz. electronic delivery of documents, electronic voting, and electronic meetings.

Electronic delivery of documents: Brimer (2006) contends that if reports are delivered electronically, then it can be ensured that they are delivered well in time and will be effectively used in making decisions. Through the Internet, small shareholders get an easy access to all the documents and news that are required to be in public domain as going to the office of registrars for small stakes is though necessary but is rarely chosen by retail shareholders (Cross 2004). Reynolds (2000) agrees that e-communication is not only speedy, easy and convenient but also provides numerous creative options to deliver data and information. Beuthel (2006) suggests that one huge aspect to be taken care of is the security concern. Company before going online has to ensure that notices are sent to invite only legitimate members and that only those members participate electronically. Chritchley (2000) highlighted that Independent Investors Communication Corp (IICC), a subsidiary of Automated Data Processing Inc. found out that electronic delivery would save \$8 on every delivery. In the Indian context, Sadashivam (2010) found that, as a result of MCA21, waiting time and percentage of people involved in bribery have significantly reduced whereas overall governance score improved by $27 \%$ approximately. It is suggested that heavy promotion of these ideas is required for greater awareness, processes need to be simplified for ease of going online, a series of FAQs on the company's website will be really helpful, citizens need to be educated from very beginning about the usage and functioning of modern technology, IT clubs could be formed in every state for easy e-access and stakeholders should be encouraged to participate in laying down and structuring the foundation of corporate egovernance. 
Electronic voting: Beuthel (2006) proposed that it is inexpensive and convenient for foreign investors. Shareholders can be easily motivated to vote electronically, but it is harder for old shareholders because of the age factor and resistance to change. It shall be ensured that no unauthorized person could get in anywhere in the entire procedure, systems do not break down while voting, for decision would get void and prove to be unsatisfactory. An IT expert would have to be appointed for ensuring the authenticity of participants. Lonck and Jos (2004) explains that online voting may lead to larger turnout as members who stay at far off places or who are ill or physically challenged could also cast their votes. It is not only convenient to cast the vote electronically, but processing the votes and preparing the result also becomes easier. Birch, Cockshott, and Benaud (2014) put across that voting through text messages is even cheaper. Mahoney D. M. (2001) suggests that electronic shareholder communication is highly likely to lead to increased efficiency and reduced costs. Baston and Ritchie (2004) rejected electronic voting as a 'sticking plaster' solution and refused to accept the idea that electronic voting increases voter participation because the establishment of a strong network is a pre-requisite to successfully adopt electronic voting. If any technical mistake comes up, it could have the potential to destroy the entire process. Also, adequate safeguards will be required to ensure that nobody misuses the opportunity to distort or influence the casting or counting of votes to the prejudice of anyone. Sinha (2014) describes that e-voting in companies is very desirable because of the speed, accuracy, easy accessibility and wide participation it brings with itself, but something else also comes with it, i.e. risk of hacking and manipulation which in turn needs secured platforms, certified procedures and vigilant supervision. Flipside is that voting card and link to annual report and other communication are sent via e-mail and shareholder is expected to go through the reports before casting the vote, but out of reluctance and resistance, shareholder anyway casts the vote without going through any material, while if shareholder would be present in person, then he obviously would cast an informed vote. Moreover, in Germany, only 29\% of companies found that e-voting has only marginally increased voter turnout (Brimer 2006).

Electronic meetings: Bostrom, Anson and Clawson (1992) set forth that a "meeting" is defined as a goal or outcome directed interaction between two or more people (teams, groups) that can take place in any of four environments (same time/same place, same time/different place, different time/same place and different time/different place). Amey and Mozley (2012) presented that the Council of Institutional Investors (CII) in 2010, came out with a policy that online general meetings should be allowed to complement and not substitute physical general meetings. There are two ways of using technology for conducting the meetings. Firstly, an approach where along with date and time, a physical place is chosen with an option that members can participate either physically or electronically, called a hybrid meeting. Secondly, an approach where no physical place is chosen for the meeting and everybody has to have an electronic presence called a virtual meeting. Cross (2004) provided that for successful implementation of these ideas, regulatory bodies and the law governing the companies need to draft the corporate governance rules keeping in the mind the dynamics of technology. Jessup and Valacich (1992) contributed that productivity, access to participants, turnout, and ability to monitor and intervene, etc. are some of the factors to be borne in mind while deciding the mode of meeting. Beuthel (2006) proposed that challenge to be addressed in an e-meeting is its vulnerability to chaos if shareholders put up too many arguments and comments. A solution could be to set a minimum percent of holding to have a right to free speech or a minimum number of years of association with the company. Virtual meetings could be conducted once the law provides for it and security levels and internet networks are protected. After that, company can work on the provision of creating shareholder id and password on its website; which after logging in, will provide details of links to detailed 
procedures and description of preferred networks and systems, link to join the live AGM, icons to post the questions during the meeting and cast the final vote at the end, supported with planned demos already uploaded for the entire process and webcast of complete meeting for reasonable time period for control and decision making. In Germany, from 1998-2005, the number of shareholders was increased by around $60 \%$ and shareholders' presence in general meetings fell down by $25 \%$. Reasons analyzed were dispersed shareholding, immobility of foreign investors, small shareholders' lack of belief in making a change and their unwillingness to spend time and money. In Germany and Switzerland, more than $60 \%$ of shareholders agreed to be present in general meetings and voting if an electronic option is given. Remp (1974) reported that chance of conflicts in an e-meeting is high because of inadequate turns with a person to speak. The results showed that the percentage of electronic participants agreeing to the chairman's effectiveness was $18 \%$ lesser than the percentage of face-to-face participants.

\section{Research Gap}

The essence of most of the studies cited above is about the utility of electronic tools of corporate governance along with the safeguards to be adopted for their effective implementation. In India, the facilitation of these mechanisms has been incorporated in the law after the enactment of Companies Act 2013 and company secretaries have been allotted the duty to comply with the provisions thereof. In order to reduce the information asymmetry amongst varied stakeholders and especially shareholders, the provisions of electronic meetings, electronic delivery of document and e-voting have been added. However, these initiatives will prove to assume a significant role, only if they are used by the shareholders. Thus, the present study has been undertaken to delineate the factors influencing the shareholders to make use of the e-tools while taking guidance from the company secretaries on the same. In India, no such study has been taken up in this domain providing empirical evidence encouraging the usage of mediums of e-governance.

\section{Need for the study}

It is indispensable to escalate the degree of participation and activism of the retail shareholders in governing the companies which currently is unsubstantial. In order to improve the situation, the need of the hour is to leverage technology to increase the threshold of an acceptable level of corporate governance in the country. In India, use of technology in corporate governance has already featured mechanization in the several rules and regulations governing Indian companies. The multiple numbers of responsibilities have been levied on the company secretaries in this respect. However, the shareholders are not making the most of it. Thence the rationale behind this study is to provide a comprehensive analysis of the opinion of shareholders and company secretaries on various such available electronic mechanisms and to analyze the factors which impact the shareholders to electronically pursue their duties so as to make them constructively effectual from indifferently dormant.

\section{Objectives of the study}

The present study has been undertaken to analyze the opinion of the shareholders on the electronic delivery of documents, electronic voting and, electronic general meetings; to study the perceptions of company secretaries on electronic delivery of documents, electronic voting and newly introduced provisions on electronic board and electronic general meetings; to compare the opinions of shareholders and company secretaries on different aspects of electronic delivery of documents, electronic voting and electronic meetings. 


\section{RESEARCH METHODOLOGY}

This section expounds the methodology used in the study along with the tools used to conduct the analyses.

This study is a survey-based research. Both primary and secondary data have been used for the study. For primary data collection, the study relied on both quantitative and qualitative analyses. Two questionnaires were designed for the study, of which, one was addressed to the shareholders and second to the company secretaries. In pilot testing, responses were gathered from 34 shareholders and 36 company secretaries. Final questionnaires were sent to 250 shareholders and 205 company secretaries. Complete responses were received from only 208 shareholders and 150 company secretaries from June 2015 to June 2017. Telephonic and face-to-face interviews were also conducted with 7 shareholders and 7 company secretaries. Along with the primary data, secondary data including various books and articles on corporate governance was also reviewed.

Reliability analysis: For both the surveys, Cronbach's Alpha coefficients have been found to be higher than 0.7 (Burns and Burns 2008). The validity of the questionnaires, i.e., checking that they measure what they claim to measure, has been ensured by the development of statements on the basis of the review of literature and interviews of the experienced shareholders and company secretaries.

Tools used: For quantitative analysis, five tools have been applied using SPSS 21, namely, logistic regression, binomial test, independent sample t-test, one sample test and frequency tables. For qualitative analysis, the tool of phenomenological analysis has been used.

HYPOTHESES OF THE STUDY: Following are the hypotheses divided into three categories - 'for shareholders', 'for company secretaries' and 'for both'.

For shareholders:

$\mathrm{H}_{01}$ : The choice of mode for delivery of documents, for voting on resolutions and for attending general meetings is symmetric across genders and for different categories of years of investment experience.

$\mathrm{H}_{02}$ : There is no significant role of the level of comfort with electronic delivery, the impact of electronic delivery on the environment, ease of use associated with electronic delivery and impact of electronic delivery in reducing costs on the preference of shareholders for electronic delivery.

$\mathrm{H}_{03}$ : Contribution of electronic initiatives to good governance, ease of use associated with electronic voting, belief of no risk of security breaches in e-voting and belief in no issue of evotes being less-informed do not contribute significantly to the preference of shareholders for electronic voting.

$\mathrm{H}_{04}$ : Contribution of electronic initiatives to good governance, belief in no higher risk of conflicts in e-meeting and impact of electronic meetings in reducing costs do not contribute significantly to the preference of shareholders for electronic meetings. 


\section{For company secretaries:}

$\mathrm{H}_{05}$ : The choice of mode for delivery of documents, for voting on resolutions and for attending the board meetings and general meetings is symmetric.

For both:

$\mathrm{H}_{06}$ :The favorable opinion among the shareholders and company secretaries on electronic delivery of documents, electronic voting and electronic general meetings is symmetric.

$\mathrm{H}_{07}$ : There is no difference between shareholders and company secretaries with respect to the opinion on the impact of electronic delivery, electronic voting and electronic general meetings in reducing costs.

$\mathrm{H}_{08}$ : Opinion on the contribution of electronic initiatives to good governance is similar from shareholders' and company secretaries' perspective.

\section{DATA ANALYSIS}

This section provides details about the factors influencing the perspective of shareholders towards electronic mode, presents the outlook of company secretaries on various aspects of egovernance and compares the viewpoints of shareholders and company secretaries on the favourableness of electronic initiatives followed by the results of a phenomenological analysis.

\section{Analysis of the shareholders' perspective on e-corporate governance:}

A binomial test has been conducted to test whether there is any statistical difference between the choices for the two modes among the shareholders. The test has shown that p-value for all three initiatives is 0.000 which is less than .01 ; therefore, the null hypotheses $H_{01}$, stating that the choice of mode for delivery of documents, for voting on resolutions and for attending general meetings is symmetric, has been rejected.

\section{Model 1: Logistic regression for the opinion of shareholders on electronic delivery of documents}

Opinion on electronic delivery of documents $=\mathrm{f}$ (gender, number of years of investment experience, the impact of electronic delivery on the environment, level of comfort with electronic delivery, ease of use associated with electronic delivery, the impact of electronic delivery in reducing costs).

\section{Model 2: Logistic regression for the opinion of shareholders on electronic voting}

Opinion on electronic voting $=\mathrm{f}$ (gender, number of years of investment experience, the contribution of electronic initiatives to good governance, ease of use associated with electronic voting, no risk of a security breach in e-voting, no issue of e-votes being lessinformed).

\section{Model 3: Logistic regression for the opinion of shareholders on electronic general meetings}

Opinion on electronic general meeting $=\mathrm{f}$ (gender, number of years of investment experience, the contribution of electronic initiatives to good governance, no higher risk of conflicts in e-meetings, the impact of electronic meeting in reducing costs) 
For all three models, the assumptions of normality; linearity; absence of multicollinearity, heteroscedasticity, outliers and influential cases; have been checked and met. Nagelkerke R square has come out to be $0.539,0.811$ and 0.462 respectively for the model 1,2 and 3 . Hence, it can be said that models are moderately fitting the data. The analyses of the models are presented in the table below (Table 1).

TABLE 1 Results of Logistic Regression

\begin{tabular}{|l|r|r|l|r|r|l|r|r|}
\hline Model 1 & \multicolumn{7}{l|}{ Model 2 } & \multicolumn{2}{l|}{ Model 3 } \\
\hline Variables & \multicolumn{1}{l|}{$\begin{array}{l}\text { Sig. (2- } \\
\text { tailed) }\end{array}$} & Exp(B) & Variables & Sig. (2-tailed) & Exp(B) & Variables & \multicolumn{1}{l|}{ Sig. (2-tailed) } & Exp(B) \\
\hline Gender(1) & .870 & .892 & Gender(1) & .611 & 1.251 & Gender(1) & .395 & 1.630 \\
\hline Yrs_Inv(1) & $.091^{* * *}$ & .271 & Yrs_Inv(1) & $.001^{*}$ & .010 & Yrs_Inv(1) & .218 & .384 \\
\hline Yrs_Inv(2) & $.022^{* *}$ & .235 & Yrs_Inv(2) & $.077^{* * *}$ & .182 & Yrs_Inv(2) & $.048^{* *}$ & .326 \\
\hline Edel_cmfrt & $.028^{* *}$ & 2.116 & Evot_info & $.001^{*}$ & 36.687 & CR_Gmeet & $.009^{*}$ & 1.850 \\
\hline Edel_ease & $.001^{*}$ & 6.046 & Evot_ease & $.002^{*}$ & 23.115 & Eini_GdG & $.065^{* * *}$ & 2.263 \\
\hline Edel_CR & $.027^{* *}$ & 2.547 & Evot_nosec & $.022^{* *}$ & 9.477 & Emeet_cnflct & $.001^{*}$ & 3.826 \\
\hline Edel_envt & .239 & .588 & Eini_GdG & .572 & .664 & Constant & .001 & .000 \\
\hline Constant & .002 & .000 & Constant & .002 & .000 & & & \\
\hline
\end{tabular}

*Significant at $1 \%$ level of significance

**Significant at $5 \%$ level of significance

*** Significant at $10 \%$ level of significance

Source: SPSS Output

For model 1, following is the interpretation of the significant variables: Ease of use associated with electronic delivery: $\mathrm{B}=1.799 ; \mathrm{Exp}(\mathrm{B})$ (odds ratio) $=6.046 ; \mathrm{p}=.001<.01$. If agreeableness on ease of use associated with electronic delivery increases by 1 point on the Likert scale, shareholders are 6.046 times more likely to opt for electronic mode over physical mode. Therefore, the null hypothesis $\mathrm{H}_{02}$, stating that there is no significant role of ease of use associated with electronic delivery on the preference of shareholders for electronic delivery, has been rejected; Second category of number of years of investment experience (5-10 years): $\mathrm{B}=-1.035$; Exp (B) (odds ratio) $=.271 ; \mathrm{p}=.091<.10$. As years of investment experience increase from base category (less than 5 years) to second category (510 years), odds in favour of physical mode over electronic mode are $1 / .271=3.69$, i.e. shareholders with 5-10 years of experience are 3.69 times more likely to choose physical mode over electronic mode for receiving communication from the companies. Therefore, the null hypothesis $H_{01}$, stating that the choice of mode for delivery of documents is symmetric for different categories of years of investment experience, has been rejected; Third category of number of years of investment experience (11-20 years): B = -1.449; Exp (B) (odds ratio) = $.235 ; \mathrm{p}=.022<.05$. Therefore, the null hypothesis $H_{01}$, stating that the choice of mode for delivery of documents is symmetric for different categories of years of investment experience, has been rejected; Level of comfort with electronic delivery: $\mathrm{B}=.749$; Exp (B) (odds ratio) = $2.116 ; \mathrm{p}=.028<.05$. Therefore, the null hypothesis $H_{02}$, stating that there is no significant role of level of comfort with electronic delivery on the preference of shareholders for electronic delivery, has been rejected; Impact of electronic delivery in reducing costs: $\mathrm{B}=$ .935 ; $\operatorname{Exp}(\mathrm{B})$ (odds ratio) $=2.547 ; \mathrm{p}=.027<.05$. Therefore, the null hypothesis $\mathrm{H}_{02}$, stating that there is no significant role of the impact of electronic delivery in reducing costs on the preference of shareholders for electronic delivery, has been rejected.

For model 2, following is the interpretation of the significant variables :Second category of number of years of investment experience (5-10 years): $\mathrm{B}=-4.611$; Exp (B) (odds ratio) $=$ $.010 ; \mathrm{p}=.001<.01$. Therefore, the null hypothesis $H_{01}$, stating that the choice of mode for voting on resolutions is symmetric for different categories of years of investment experience, has been rejected;Third category of number of years of investment experience (11-20 years): 
$\mathrm{B}=-1.704 ; \operatorname{Exp}(\mathrm{B})$ (odds ratio) $=.182 ; \mathrm{p}=.077<.10$. Therefore, the null hypothesis $H_{01}$, stating that the choice of mode for voting on resolutions is symmetric for different categories of years of investment experience, has been rejected; No issue of e-votes being less-informed: $\mathrm{B}=3.602$; $\operatorname{Exp}(\mathrm{B})$ (odds ratio) $=36.687 ; \mathrm{p}=.001<.01$. Therefore, the null hypothesis $H_{03}$, stating that belief in no issue of e-votes being less-informed does not contribute significantly to the preference of shareholders for electronic voting, has been rejected; Ease of use associated with electronic voting: $\mathrm{B}=3.140$; $\operatorname{Exp}(\mathrm{B})$ (odds ratio) $=23.115 ; \mathrm{p}=.002<.01$. Therefore, the null hypothesis $\mathrm{H}_{03}$, stating that the role of ease of use associated with electronic voting does not contribute significantly to the preference of shareholders for electronic voting, has been rejected; No risk of security in e-voting: B = .2.249; Exp (B) (odds ratio) $=9.447 ; \mathrm{p}=.022<.05$. Therefore, the null hypothesis $\mathrm{H}_{03}$, stating that belief of no risk of security breaches in e-voting does not contribute significantly to the preference of shareholders for electronic voting, has been rejected.

For model 3, following is the interpretation of the significant variables: Third category of number of years of investment experience (11-20 years): $\mathrm{B}=-1.122$; $\mathrm{Exp}$ (B) (odds ratio) = .326 ; p-value $=.048<.05$. Therefore, the null hypothesis $H_{01}$, stating that the choice of mode for attending the general meetings is symmetric for different categories of years of investment experience, has been rejected; Impact of electronic meetings in reducing costs: $\mathrm{B}=0.615$; $\operatorname{Exp}(\mathrm{B})($ odds ratio $)=1.850 ; \mathrm{p}=.009<.01$. Therefore, the null hypothesis $\mathrm{H}_{04}$, stating that the impact of electronic meetings in reducing costs does not contribute significantly to the preference of shareholders for electronic meetings, has been rejected; No higher risk of conflicts in e-meetings: $\mathrm{B}=1.342 ; \operatorname{Exp}(\mathrm{B})$ (odds ratio) $=3.826 ; \mathrm{p}=.001<.01$. Therefore, the null hypothesis $\mathrm{H}_{04}$, stating that belief in no higher risk of conflicts in e-meetings does not contribute significantly to the preference of shareholders for electronic meetings, has been rejected; Contribution of electronic initiatives to good governance: $\mathrm{B}=.817$; Exp (B) (odds ratio $)=2.263 ; \mathrm{p}=.065<.10$. Therefore, the null hypothesis $H_{04}$, stating that the contribution of electronic initiatives to good governance does not contribute significantly to the preference of shareholders for electronic meetings, has been rejected.

\section{Analysis of the company secretaries' perspective on e-corporate governance:}

A binomial test has been conducted to test whether there is any statistical difference between the choices for the two modes among company secretaries. Tests have showed that $p=.000$ for delivery of documents; $\mathrm{p}=.000$ for voting on resolutions; $\mathrm{p}=.935$ for attending board meetings and $\mathrm{p}=.463$ for attending general meetings. Therefore, the null hypothesis, stating that the choice of mode for delivery of documents and voting on resolutions is symmetric, has been rejected and the null hypothesis $H_{05}$, stating that the choice of mode for attending general and board meetings are symmetric, has been accepted.

Company secretaries' opinion on e-board meetings: Respondents were asked to mark the extent to which they agree with the statement: It was the most awaited decision for globally located directors of a company. $78 \%$ of the respondents agree with it. $75.3 \%$ of the respondents disagree with the statement that recording and preserving the proceedings of an electronically held board meeting for a year is desirable. $54 \%$ of the respondents agree that even telephones should be allowed for conducting the board meetings. They were asked to mark the type of meeting they would prefer for conducting Annual General Meetings. 65.3\% prefer a hybrid meeting. 
Analysis for comparison between the opinions of shareholders and company secretaries:

In this section, the opinion of shareholders and company secretaries has been compared on the favourableness of electronic initiatives, using independent sample t-test. Under Levene's test, if the p-value is more than .05 , the null hypothesis of equal variance assumed is accepted. For normality, the sample size is sufficiently large to invoke central limit theorem and there is no need to check the outliers as data has been collected on Likert Scale, but still the results have been bootstrapped. (Field 2013). One sample test has shown that shareholders but company secretaries are significantly favourable about electronic general meetings but for the other two, both shareholders and company secretaries are significantly favourable.

Following is the interpretation of the variables for comparison between the opinions of shareholders and company secretaries: Favourable opinion about electronic delivery of documents (Edel): The t-statistic, $\mathrm{t}(356)=-.892, \mathrm{p}=.359$ is more than .05 , hence, the null hypothesis $\mathrm{H}_{06}$, stating that the favourable opinion among shareholders and company secretaries on electronic delivery of documents is symmetric, has been accepted; Favourable opinion about electronic voting (Evot): The t-statistic, t (356) $=3.162, \mathrm{p}=.001$ is less than .01 , hence, the null hypothesis $H_{06}$, stating that the favourable opinion among shareholders and company secretaries on electronic voting is symmetric, has been rejected; Favourable opinion about electronic general meetings (Emeet): The t-statistic, $\mathrm{t}(355.46)=7.503, \mathrm{p}=$ .001 is less than .01 , hence, the null hypothesis $H_{06}$, stating that the favourable opinion among shareholders and company secretaries on electronic general meetings is symmetric, has been rejected; Favourable opinion about impact of electronic delivery in reducing costs (CR_Edel): The t-statistic, $\mathrm{t}(356)=1.792, \mathrm{p}=.083$ is less than .10 , hence, the null hypothesis $H_{07}$, stating that there is no difference between shareholders and company secretaries with respect to the opinion on the impact of electronic delivery in reducing costs, has been rejected; Favourable opinion about impact of electronic voting in reducing costs $\left(C R \_\right.$Evot): The t-statistic, $\mathrm{t}(239.35)=4.105, \mathrm{p}=.001$ is less than .01 , hence, the null hypothesis $H_{07}$, stating that there is no difference between shareholders and company secretaries with respect to the opinion on the impact of electronic voting in reducing costs, has been rejected; Favourable opinion about impact of electronic general meetings in reducing costs (CR_Emeet):The t-statistic, $\mathrm{t}(271.17)=4.198, \mathrm{p}=.001$ is less than .01 , hence, the null hypothesis $\mathrm{H}_{07}$, stating that there is no difference between shareholders and company secretaries with respect to the opinion on the impact of electronic general meetings in reducing costs, has been rejected; Opinion about contribution of electronic initiatives to good governance (Eini_GdG):The t-statistic, $\mathrm{t}(354.05)=-1.100, \mathrm{p}=.239$ is greater than .05 , hence, the null hypothesis $\mathrm{H}_{08}$, stating that opinion on contribution of electronic initiatives to good governance is similar from shareholders' and company secretaries' perspective, has been accepted.

Shareholders' and company secretaries' opinion on different recommendations: Respondents were asked to mark the extent to which they agree with the recommendation: Demos with subtitles in different languages shall be uploaded by companies on their respective websites for different new electronic procedures. $81.3 \%$ of shareholders and $56.7 \%$ of the company secretaries have agreed with it. $81.8 \%$ and $71.3 \%$ of the respective respondents agree with the recommendation that toll-free number shall also be provided by each company for asking questions during e-voting window and e-meetings as toll-free numbers of NSDL/CDSL are of little use. Respondents were asked to mark the extent to which they agree with the recommendation: Some private players should be introduced to 
complement the functioning of NSDL, CDSL \& Karvy. 60\% of the company secretaries agree with it. $83.6 \%$ of the shareholders and $66.7 \%$ of the company secretaries agree with the recommendation that educating shareholders about various concepts of an electronic interface is the need of the hour.

\section{Results based on phenomenological analysis:}

For the study, 7 shareholders and 7 company secretaries were interviewed. Open-ended questions based on the theoretical footing of the study were asked of each interviewee. Based on phenomenological analysis, following eight themes have been developed after analyzing the interviews of company secretaries and shareholders: Shareholder communication has become more or less easy but has led to a bit of confusion since 2006; Change from TCS to Infosys has been found to be quite undesirable; Access to good speed internet is one of the hindrances for e-meetings; Electronic board meetings are always a second choice; Board meeting through video conferencing is a welcome move but not its accompanying unnecessary stringent rules; Food, gifts, and vouchers are the only agenda in AGM for shareholders; Voting exercise can be made more meaningful; Teleconferencing should be allowed to conduct board meetings to be at par with other economies.

\section{FINDINGS AND IMPLICATIONS}

Focusing on both the sides of the table, i.e. explicating the perspectives of both the beneficiaries and the guardians of corporate governance, following are the findings, interpretations and implications based on the responses of shareholders first, then based on the responses of company secretaries and then based on both, for each of the electronic initiatives.

\section{Electronic delivery of documents:}

For shareholders: More than $70 \%$ of the shareholders prefer electronic delivery over paper delivery. No difference in the choice of mode has been found based on gender. There is no difference in choice between the two modes for shareholders having up to 10 years of investment experience. However, shareholders with 11-20 years of investment experience prefer physical mode around 4.3 times more than the electronic mode for delivery of documents as compared to the shareholders with less than 5 years of experience. This implies that older shareholders are more comfortable with the paper form of communication and are not receptive to adopt new mode due to lack of ease and comfort with e-means. Impact of electronic delivery on the environment has no significant impact on the preference of shareholders for the electronic mode. Many research papers have proved that paper savings are huge with an electronic circulation of reports, as also agreed by $95.3 \%$ of shareholder respondents and, it is very well accepted that there is a severe need to save trees by saving paper. Despite the dire need to protect the environment, this factor has come out to be insignificant, which necessitates that the readers of documents must be encouraged to access the electronic documents. The companies may also highlight their contribution towards carbon footprints and its benefits accrued to the company in varied forms.

As shareholders get more comfortable with the electronic interface, they will prefer it 2.12 times more than the physical mode, because as they get more comfortable with reading from the screen, their inclination towards electronic mode will get higher .As shareholders' level of ease with e-means increases, their preference for electronic delivery is 6.05 times stronger than for printed delivery, because as they start experiencing that with electronic delivery, it is 
easier to access, compare and retain the reports and, there is negligible risk of losing the reports in transit; they may start appreciating the electronic delivery more. As the shareholders become convinced with the fact that due to electronic communication, the company is being able to prevent a lot of printing and postal expenses, they will start preferring electronic delivery by more than 2.5 times. Therefore, the impact of electronic delivery in reducing costs can be said to have a significant impact on the preference of shareholders towards electronic mode.

It is important to know which factors are positively influencing the shareholders towards electronic delivery of documents so that while spreading awareness among the shareholders about its benefits, a deeper emphasis is made on the factors which influence them towards electronic mode. Here, the influencing factors were: Level of ease and comfort with electronic delivery and its impact on cost reduction. Also, its impact on the environment needs to be deliberated at a large scale. The purpose of spreading awareness will be easier to achieve if complemented with visible supporting actions. Here such actions can be: level of ease can further be increased by giving an easier access through a simple link to quickly download the software required to open the report and ensuring that reports are not unnecessarily protected with multiple passwords unknown to the shareholders (as told by one of the interviewees).

For company secretaries: More than $68 \%$ of them have chosen the electronic mode. Company secretaries work for delivering the documents. They work for electronically filing the statements, accounts, reports and other documents. Based on the qualitative phenomenological analysis, company secretaries were found to be saying that MCA helpdesk is not at all capable of addressing our queries." It seems like ministry is not well-equipped to support smooth e-filing of documents. It implies that a committee should be formed to redress such issues and bring uniformity and ease in adopting electronic measures.

For both: One of the eight themes found by phenomenological analysis is: Shareholder communication has become more or less easy but has led to a bit of confusion since 2006. Indian law has provided the companies with an option of sending annual reports and other documents in the electronic mode to the shareholders through the green initiatives which were notified by MCA in 2011. On the basis of the interviews of the company secretaries, it has been found that a few companies send the reports electronically and some physically; and on the basis of interaction with the shareholders, attention was brought to the fact that some of them do not receive any communication from any company in printed or electronic mode and some of them receive the documents in both the forms. Hence, what could be implied is that, either shareholders are not careful about their rights or they do not update their email or residential addresses with the depositories or probably some companies are using the transition to be the loophole for not sending any communication at all and for not complying with the provisions of the act in the full spirit. These hitches need to be looked into by the lawmakers.

Shareholders stated that "as today also some companies send printed annual reports to the shareholders which are never read and ultimately go into the trash, provisions like shareholders holding at least 100 shares shall be sent annual reports by post (if post is specified as the mode by the shareholder) and others can access the reports on the website, should be introduced." Such provisions could be introduced after checking their need and feasibility. The opinions of both the shareholders and the company secretaries are significantly positive about electronic delivery and its impact on reducing costs. It is consistent with the finding by Chritchley (2000), that electronic reports would save \$8 on 
every delivery. Using an independent sample t-test, it has been found that shareholders have a more favourable opinion probably because of all the inconvenience associated with e-filing, is being faced by the company secretaries.

\section{Electronic voting}

For shareholders: More than $80 \%$ of the shareholders have chosen the electronic mode. No difference in the choice of mode has been found based on gender. Shareholders with 5-10 years of investment experience prefer physical mode 100 times more than the electronic mode as compared to the shareholders with less than 5 years of investment experience. This means that newest shareholders trust the technology and relatively older shareholders think that actually going to the meeting and then casting the vote is more meaningful. Shareholders having 11-20 years of investment experience and shareholders with less than 5 years of experience, choose whatever mode they find desirable and convenient every time. As shareholders' level of ease with e-means increases, their preference for electronic voting is 23.12 times stronger than for physical voting, because as they start to believe in the ease, satisfaction, and convenience which e-voting provides by saving travel time, they get more inclined towards it. To make it extremely effortless for the shareholders, companies should upload demos of remote e-voting on their websites, as agreed by $81.3 \%$ of shareholders and $56.7 \%$ of company secretaries and, also provide toll free numbers to ask any queries during evoting window, as agreed by $81.8 \%$ of shareholders and $71.3 \%$ of company secretaries. The shareholder also suggested the use of the mobile platform for e-voting through instant message facility.

Using a 5\% level of significance, it has been found that if shareholders believe that there are no security issues with remote e-voting, they will like it around 9 times more than physical voting. $88.2 \%$ of shareholders and $82 \%$ of the company secretaries agreed with the statement that some high-security systems should be mandated for e-voting. This means that shareholders want their votes to reach safely for making decisions and want to feel convinced that there are lesser chances of votes getting lost in transit unlike under postal ballot. It is interesting to note here that in the UK; electronic voting was started to be adopted by the companies from 2004 after a huge number of physical votes started going missing. If shareholders believe that e-votes are equally informed as like physical votes, then they are around 37 times more likely to choose electronic voting. As told in the interviews also, that going to the meeting and casting the vote after full-fledged discussions is very satisfactory, hence; if all the important aspects and other information about the proposed resolutions are easily available to the shareholders online, they will readily switch to remote e-voting. More than $80 \%$ of shareholders prefer electronic voting over physical voting, but of them, around $30 \%$ have actually used it. Brimer (2006) also found that in Germany, only $29 \%$ of companies found that e-voting has only marginally increased the voter turnout. It is therefore important to know which factors are positively influencing the shareholders towards electronic voting so that while spreading awareness among the shareholders about its benefits, a deeper emphasis is made on the factors which influence them towards electronic mode. Here, the influencing factors are Level of ease, no risk of security and no risk of evotes being less-informed. During the interviews, small shareholders said that 'majority of them think that their votes will not make any difference; hence, for improved shareholder participation, some criteria like minimum 20\%-25\% votes on resolutions from minority shareholders should be introduced in law and it should be made compulsory for a shareholder to vote and if a shareholder has not voted for three times, his rights as a shareholder should be taken away. 
For company secretaries: More than $90 \%$ of them have chosen an electronic mode.Based on the qualitative analysis of interviews of company secretaries, they have been found to be saying - "There is a need to reduce the fees structure given by NSDL/CDSL and scrutinisers for availing their services; use of Investor Education and Protection Fund should be made for the purpose of conducting e-voting across India; all the voting should ideally be done after the general meeting when everyone gets to know about the pros and cons of the resolutions as under the present structure of e-voting, resolutions once uploaded cannot be changed; security would be an issue as technical people will also be involved who might not be equipped with interpreting security breach.”

For both: Using independent sample t-test, the opinion of shareholders and company secretaries on the favorableness of electronic voting and impact of electronic voting in reducing costs has been compared and it has been found that their opinions differed significantly. Company secretaries have a lesser favourable opinion. This is because of the increased responsibilities and the fact that companies have to pay a huge amount to the agencies - NSDL/CDSL/Karvy and to the scrutinisers and has to provide the voting platform in multiple ways. This finding is consistent with the result of the study by Beuthel (2006), that higher than $75 \%$ of companies believed that electronic initiatives will raise the costs for they would have to install necessary infrastructure. $60 \%$ of the company secretaries, therefore, agreed with the recommendation that other private players should also be introduced to complement the functioning of the three agencies so as to reduce the costs.

Electronic meetings: Two kinds of company meetings are: electronic board meetings and electronic general meetings.

Electronic board meetings: Overall, company secretaries do not view the two kinds of meetings differently. However, after splitting the data on the different basis, it has been found that company secretaries with less than 5 years of experience and practicing company secretaries are more willing to trust and use the technology by choosing electronic board meetings. Older ones rely more on traditional methods. On the basis of qualitative analysis: All the company secretaries who have been interviewed said that "electronic board meetings are their second choice. They have to conduct them either just to enable a director outside India to participate or to meet the legal requirement of a quorum. The reason behind this hesitation is the condition attached with the clause on electronic board meetings. The clause is that board meetings could be conducted by audio-visual means capable of recognising and recording the participation of directors and proceedings of meetings. A condition attached is that if something is not captured, one has to repeat it so that it could be captured. Now one doesn't know during the meeting what has not been captured. Company secretaries have been levied with too many responsibilities with respect to the technical issues, which require a dependency on other departments, which in turn could lead to a breach of security". Hence, some technical position shall also be defined in the law who would share these technical responsibilities with the company secretaries and would be equally responsible for the breach of provisions. They said that "they were waiting for the law to provide the option of electronic board meetings but now they use it only when it is necessary". With the same idea, some suggested that even telephones should be allowed to conduct meetings in order to have more flexibility because telecommunication network is better than IT infrastructure in India and even old age people who are not tech-savvy are more comfortable with telephones. 


\section{Electronic general meetings:}

For shareholders: More than $70 \%$ of the shareholders have chosen electronic meetings over face-to-face meetings. No difference in the choice of mode has been found based on gender and number of years of investment experience. Presently as per this study, more than $50 \%$ shareholders have never attended any general meeting and e-meeting is definitely a good solution in this situation as minority shareholders generally do not care to travel all the way to the place of the meeting which is generally the place of registered office of the company. But one big apprehension about e-meetings as found in the literature also has been the risk of conflicts and complications on the electronic interface. In model 3, it has been discovered that as shareholders agree more with no higher risk of conflicts in e-meetings, they are around 4 times more likely to opt for electronic mode over physical mode. So, by having proper rules and mechanisms in place for the implementation of e-meetings, if shareholders are made to believe that they will get full chance to express their views in some form and, it will be completely synchronized and managed by competent persons appointed for the purpose, then shareholders' participation in AGMs could increase immensely. Talking about the chance to speak, the researcher has collected responses to the proposed criterion - the minimum percentage of shareholding in the company or the minimum number of years of shareholding in the company. $40.4 \%$ of the shareholders and $55.3 \%$ of the company secretaries consented to prescribe minimum percentage of shareholding as the criteria to establish the right to speak for a shareholder. Hence, just like provision on class action suit under section 245 of Companies Act' 2013, after getting approval of the shareholders, certain minimum percentage of shareholding can be prescribed for the shareholders to speak during the e-meeting while others can mail the questions to a common email address of the director/ small shareholders' director who would be present at the meeting, which can then be taken up together.

As the shareholders become convinced with the fact that due to electronic meetings, a company is being able to prevent a lot of expenses involved in executing a physical meeting, they will start preferring electronic meetings by twice. Therefore, the impact of electronic meetings in reducing costs can be said to have a significant impact on the preference of shareholders towards electronic mode. It is important to know which factors are positively influencing the shareholders towards electronic meetings so that while spreading awareness among the shareholders about its benefits, a deeper emphasis is made on the factors which influence them towards electronic mode. Here, the influencing factors are no higher risk of conflicts in e-meetings and its impact on cost reduction. Also, its contribution to good governance needs to be deliberated at a large scale. Also to make it easier for the shareholders to attend an e-meeting, $81.3 \%$ of shareholders and $56.7 \%$ of company secretaries agreed that demos detailing steps involved in e-meeting shall be uploaded by the companies on their websites and; more than $60 \%$ of both agreed that companies should provide necessary equipment and network access at places where shareholders would need them to participate in e-meetings. The phenomenological analysis also gave a theme that lack of strong IT infrastructure in India is a major obstacle to introducing and vividly implementing the concept of electronic general meetings. However, it is widely accepted that the initiative of Digital India has already been started to be directed towards this cause.

For company secretaries: Company secretaries have not distinguished between physical and electronic general meetings. It is interesting to note here that in USA virtual shareholder meetings have been legalized by few states only like Delaware. As per the interviews of company secretaries, the ideal course of the general meeting and voting should be: 
Resolutions with relevant subject matter shall be uploaded in advance of the meeting. Hybrid general meetings should then witness discussion on these resolutions, and then the voting exercise should begin on the final resolutions (under present e-voting structure, discussion or any change in the resolution is not possible). Then the results shall be announced within three-four days and be mailed to the shareholders.

For both: Researcher compared the opinion of shareholders and company secretaries on the favorableness of electronic general meetings and their impact on cost reduction using independent sample t-test. Company secretaries have a lesser favorable opinion on both because they know that shareholders are interested not in the proceedings of the meeting but in food, gifts and vouchers as was consented to not only by the company secretaries but by the shareholders themselves. Company secretaries know that like electronic board meetings, electronic general meetings would also come with strict lengthy rules, huge legal and technical responsibilities and, inadequate support for them.

\section{CONCLUSION}

Electronic delivery of documents and electronic voting have already found a strong footing in the country but shareholders are not making use of them at the desired pace. Electronic meetings still need the full-fledged infrastructure, well-thought provisions, and a proper jumpstart. Although electronic board meetings have made their way a lot is yet to be done to further facilitate their easy conduct. Qualitative analysis revealed that the main problem is that the shareholders perceive their role in governing the companies to be negligible owing to their small shareholding, which should not be the case because when companies explode into scams, not only big shareholders but small shareholders also lose money which may seem little when seen on a proportionate basis to big shareholders but could be a big proportion of the whole-life investment for some shareholders. Beuthel (2006) also analysed the reasons behind the weak shareholder presence in AGMs and concluded small shareholders' lack of belief in making a change and their unwillingness to spend time and money as the major obstacles. Moreover, it is easier for big shareholders to recover their money using various ways. Companies are being required by law to spend so much time, effort and money to comply with the humungous number of rules, laws, and legislation for the benefit of the shareholders and the society, but the beneficiaries, especially the retail shareholders are hardly using their rights of casting their vote or attending meetings or checking the reports of the company before making their investment decisions. Shareholders invest in the shares of the company as per the random guidance of their brokers or financial advisors. Retail shareholder activism is very much needed for which shareholders' education is of utmost importance. Counselling and awareness sessions are required to be held to increase shareholder participation, with special emphasis on the influential factors discussed above. Spreading awareness is quintessential for all the three initiatives. $66.7 \%$ of company secretaries and $83.6 \%$ of the shareholders themselves agreed that educating shareholders about various concepts of an electronic interface is the need of the hour.

\section{LIMITATIONS OF THE STUDY}

The limitations of the study are that for every model, interaction effects between independent variables on the dependent variable could also have been tested; Impact of electronic delivery of documents, electronic voting and electronic meetings on good governance could have been judged separately; Some of the variables had to be excluded from the analysis for building the models. Backward logistic regression had been used for determining the variables to build the best model which could not be obtained with all the variables probably because of 
comparatively smaller sample size. So, sample size should have been larger for more robust application of logistic regression; The findings based on qualitative analysis could have been made more robust by increasing the number of interviewees.

\section{SCOPE FOR FUTURE RESEARCH}

Following are the areas for future research: Analysis of secondary data can be done to substantiate the findings of this study; A study on the need and effectiveness of mobile-based voting can be done; A study on "Whether teleconferencing should be allowed as a mode of conducting board meetings in India?" can be done after analyzing the provisions outside India; A study on "Comparison of Relevance of e-AGMs: India and outside India" can be taken up; A study on the increased role of company secretaries after the introduction of electronic initiatives could be done; A study on XBRL as a mandatory reporting language could be pursued.

\section{ENDNOTES:}

${ }^{\mathrm{i}}$ Beuthel, B. (2006). Meetings and Shareholder Participation in Switzerland and Germany. Dissertation, University of St. Gallen, Graduate School of Business Administration, Economics, Law and Social Sciences , Zurich.

\section{REFERENCES:}

Amey, J. H., \& Mozley, E. D. (2012, July 19). Online Shareholder Participation in Annual Meetings. (N. Noked, Ed.)

Baston, L., \& Ritchie, K. (2004). Turning out or turning off? Electoral Form Society.

Beuthel, B. (2006). Meetings and Shareholder Participation in Switzerland and Germany. Dissertation, University of St. Gallen, Graduate School of Business Administration, Economics, Law and Social Sciences, Zurich.

Birch, S., Cockshott, P., \& Benaud, K. (2014). Putting Electronic Voting under the Microscope. The Political Quarterly, 85 (2), 187-194. https://doi.org/10.1111/1467-923X.12071

Bostrom, R. P., Anson, R., \& Clawson, V. K. (1992).Group facilitation and group support systems. Group support systems: New Perspectives, 8, 146-168.

Brimer, A. G. (2006). Getting wired at SEC: Reforming the proxy process to account for new technologies. Alabama Law Review, LexisNexis Academic .

Burns, R. P., \& Burns, R. (2008). Business research methods and statistics using SPSS.Sage.

Companies Act 2013. Retrieved from http:/www.mca.gov.in/Ministry/pdf/Companies Act2013.pdf

Chritchley, B. (2000, December 19). More room in your mailbox: Investors can vote, get correspondence equally. (Tuesday National Editions) . (N. Post, Compiler) Canada: LexisNexis Academic.

Cross, S. R. (2004). Corporate governance, information technology and the electronics company in the United Kingdom. Information and Communications Technology Law, 13 (2). https://doi.org/10.1080/1360083042000210541

Field, A. (2013). Discovering Statistics Using IBM SPSS Statistics. (M. Carmichael, Ed.) Sage Publications Ltd.

Jessup, L. M., \& Valacich, J. (1992). Group Support Systems: New Perspectives. Prentice Hall Professional Technical Reference.

Loncke, M., \& Jos, D. (2004). Online Voting: A Legal Perspective. International Review of Law Computers and Technology, 18 (1), 59-79. https://doi.org/10.1080/13600860410001674742 
Mahoney, D. M. (2001). Implementing an electronic delivery and shareholder communications program. Insights; the Corporate \& Securities Law Advisor, 15(12), 15.

Reynolds, P. (2000). Fair, fast and immediate: electronic reporting and the dawn of the private investor. Business Information Review, 17 (2), 66-71. https://doi.org/10.1177/0266382004237539

Sadashivam, T. (2010). A New Paradigm in Governance: Is it true for E-Governance. Journal of the Knowledge Economy, 1 (4), 303-317. https://doi.org/10.1007/s13132-010-0018-3

Sinha, A. B. (2014, July 4). E-Voting: A New Dimension in Corporate Voting Process. e-CS Nitor, 1(3). ICSI. 